\title{
Variation in female guppy preference for male olfactory and visual traits
}

\author{
Aya Sato $\cdot$ Naoko Ozawa $\cdot$ Kenji Karino
}

Received: 20 November 2013/Accepted: 31 March 2014/Published online: 12 April 2014

(C) Japan Ethological Society and Springer Japan 2014

\begin{abstract}
Animals often use different sensory systems to assess different sexually selected signals from potential mates. However, the relative importance of different signals on mate choice is not well understood in many animal species. In this study, we examined the relative importance of male olfactory and visual cues on female preference in the guppy Poecilia reticulata. We used digitally modified male images to standardize visual stimuli. We found that regardless of whether females were presented without male visual stimuli or with identical male visual stimuli, they preferred stimuli with the odor of males to those without. However, when females were allowed to choose between dull male visual stimuli with male odor, and brightly colored male visual stimuli without male odor, there was no clear preference for either. Some females preferred the dull male visual stimuli with male odor, whereas some other females preferred the brightly colored male visual stimuli without male odor. These results indicate that the relative importance of olfactory and visual cues in female mate preference varied between individuals.
\end{abstract}

Keywords Mate choice - Olfactory signal - Visual signal - Individual variation - Poecilia reticulata .

Dichotomous choice experiment

\section{Introduction}

In general, females are the choosier sex, and they can obtain direct and/or indirect benefits when choosing mates

\footnotetext{
A. Sato $\cdot$ N. Ozawa $\cdot$ K. Karino $(\bowtie)$

Department of Biology, Tokyo Gakugei University,

Nukui-kita 4-1-1, Koganei, Tokyo 184-8501, Japan

e-mail: kkarino@u-gakugei.ac.jp
}

(Andersson 1994; Andersson and Simmons 2006). Therefore, male signals that are used as mate choice criteria by females should be honest indicators of male quality (Zahavi 1975; Hamilton and Zuk 1982). Females often use multiple traits to assess males (reviewed by Candolin 2003). Multiple message hypothesis expects that the phenotypic and/or genetic quality of males with several sexually selected traits can be more reliably assessed by females rather than those with a single sexually selected trait, because different traits may convey different types of information about the male (Candolin 2003). In addition, females of some animal species are known to use multimodal sensory systems to assess different types of signals from males, such as visual, acoustic, and chemical signals (Andersson 1994). However, little empirical evidence has been found regarding the relative importance of multiple male signals in female mate choice (Pryke et al. 2001; Wagner and Basolo 2007; Heushele et al. 2009), especially, regarding the relative importance of different sensory modalities in female choice (Kodric-Brown and Strecker 2001; McLennan 2003; Plenderleith et al. 2005; Simmons et al. 2013).

In recent decades, olfactory signals have attracted considerable attention in the study of species recognition, mate recognition, and mate assessment (McLennan 2003; Plenderleith et al. 2005; Wong et al. 2005; Constanzo and Monteiro 2007; Johansson and Jones 2007). In particular, olfactory signals are important for mate choice in some insect, fish, and mammal species (Plenderleith et al. 2005; Johansson and Jones 2007; Strandh et al. 2012; Simmons et al. 2013). In some fishes, females can assess the genetic compatibility of potential mates, such as the MHC (major histocompatibility complex), by using male olfactory cues (Landry et al. 2001; Aeschlimann et al. 2003; Forsberg et al. 2007; Agbali et al. 2010; Bahr et al. 2012). 
In addition, females use olfactory cues for assessing other aspects of male quality. For example, in the swordtails Xiphophorus birchmanni, females can discriminate between well-fed males and food-deprived males by their odors (Fisher and Rosenthal 2006). Females of the threespined stickleback Gasterosteus aculeatus can discriminate between males with nests and males without nests solely by olfactory cues (Häberli and Aeschlimann 2004). The interaction between olfactory and visual signals from males in mate choice context has been investigated in several fish species. For instance, females of the swordtail Xiphophorus pygmaeus prefer olfactory cues from conspecific males to those from heterospecific males when they are presented only with olfactory cues (Hankison and Morris 2003). However, when male visual cues are presented to the females, they prefer heterospecific males, possibly because of the female preference for large males in this species (Hankison and Morris 2002). In contrast, females of another swordtail $X$. continens prefer olfactory cues of heterospecific males to conspecific olfactory cues (McLennan and Ryan 2008). In pupfishes, females of both Cyprinodon maya and C. labiosus prefer the olfactory cues of conspecific males to those of heterospecific males, and females of $C$. maya also prefer conspecific visual cues, but C. labiosus females do not discriminate between conspecific and heterospecific males based on visual cues (Kodric-Brown and Strecker 2001). These findings suggest that the relative importance of olfactory and visual signals in female mate preferences may differ among species, although it remains unclear in many fishes.

In the present study, we examined the relative importance of male olfactory and visual cues in female mate preference in the guppy Poecilia reticulata. The guppy is a live-bearing poeciliid fish, and males assume conspicuous color spots on their bodies. The use of male visual signals in female mate choice, such as color spot patterns and courtship displays, are well documented in this species (Houde 1997). In particular, orange spot patterns of males are known to be an important mate choice criterion of females in many guppy populations (Houde 1987; KodricBrown 1989; Endler and Houde 1995; Grether 2000; Evans et al. 2004a). The role of olfactory signals in mate choice in guppies has been investigated in previous studies. For example, females presented with olfactory stimuli from males and females initially associate with the female stimulus; however, they subsequently reverse their preference (Shohet and Watt 2004). Shohet and Watt (2004) also reported a negative correlation between female preference for male olfactory cues and that for visual cues, i.e., olfactory attractive males were not preferred visually. In another study, male guppies assess the mating status of females by olfactory cues and prefer virgin females to mated females (Guevara-Fiore et al. 2009).
Here, we examined the relative importance of olfactory and visual cues of male guppies in female preference by using digitally modified male images to standardize the visual stimuli. The efficacy of digitally modified male images to examine female preference in the guppy has been previously demonstrated (Nicoletto and Kodric-Brown 1999; Karino et al. 2010). We conducted 3 dichotomous choice experiments: (1) female preference based on male olfactory cues only; (2) female preference based on male olfactory cues with identical male visual cues; and (3) female preference based on male olfactory cues versus visual cues. In the third experiment, we presented a dullcolored male image with male odor and a brightly colored male image without male odor to females. We predicted that if females prioritized olfactory cues over visual cues, they would prefer the dull-colored male image with male odor. On the other hand, since females in the study population had visual preference for colorful males (Karino et al. 2010), they would prefer the brightly colored male image without male odor if they prioritized visual cues.

\section{Materials and methods}

\section{Study subjects}

We used laboratory-reared, first- or second-generation descendants of feral guppies from the Hiji River $\left(26^{\circ} 43^{\prime} \mathrm{N}\right.$, $128^{\circ} 11^{\prime} \mathrm{E}$ ), Okinawa, Japan. Females from this population are known to prefer males with large orange spots with high color saturation (Karino et al. 2010). Fish were housed in the laboratory at Tokyo Gakugei University in water at 24-26 ${ }^{\circ} \mathrm{C}$ and under $12: 12 \mathrm{~h}$ photoperiod. Fully mature, virgin females from single-sex aquaria were used, since pregnant females are unreceptive to males (Houde 1997). Because females that mature without ever seeing males often mate indiscriminately in the first encounter with males (Houde 1997), all test females were exposed to 50-60 adult males through a clear partition 1 day before the experiment.

\section{Olfactory and visual male stimuli}

We used water with and without male odor as the olfactory stimuli. We obtained water with male odor by placing three adult males in a tank $(14 \times 14 \times 10 \mathrm{~cm})$ containing $1000 \mathrm{ml}$ dechlorinated water for $24 \mathrm{~h}$. The three males were randomly chosen from stock aquaria. To avoid food contamination, the males were not fed in the tank. Water without male odor was obtained from a fishless tank that had contained $1000 \mathrm{ml}$ of dechlorinated water for $24 \mathrm{~h}$. Stimulus water with or without male odor from a single tank was used to test 3-4 females. We used individual males only once to produce stimulus water. 
Digitally modified male images that had previously been used in other experiments (Karino et al. 2010) were used as the visual stimuli. We chose successive frames $(60 \mathrm{~s}$ in length, 30 frames/s) of behavioral sequences of a male, in which the male exhibited typical sigmoid courtship displays. We adjusted total length of the male image to $24.0 \mathrm{~mm}$, which is the average total length of males in the natural habitat in this population (Karino et al. 2010). We created bright and dull male images. In the bright male image, orange spot size (relative orange spot area to total body and caudal fin area) and color saturation were increased to 14.3 and $91.0 \%$, respectively. The dull male image was created by reducing orange spot size and color saturation to 8.7 and $41.0 \%$, respectively (see Karino et al. 2010 for detailed methods). The visual mate preferences of females in this population can be detected using these male images, i.e., females prefer the bright male image over the dull male image (Karino et al. 2010).

\section{Experimental apparatus}

We used a glass aquarium $(15 \times 28 \times 20 \mathrm{~cm})$ for the experiment. We placed an opaque board at the bottom of the aquarium. We also placed a color liquid crystal display monitor (FlexScan L367; Eizo, Japan) at a distance of $3 \mathrm{~cm}$ from the aquarium (Fig. 1). Two male images were simultaneously presented to a test female from right and left sides (each were $10 \mathrm{~cm}$ wide $\times 6 \mathrm{~cm}$ high) of the monitor. We set an area of $10 \times 5 \mathrm{~cm}$ as a preference zone in front of each male image (Fig. 1). The aquarium contained water to a depth of $6 \mathrm{~cm}$ and water temperature was maintained at $24-26{ }^{\circ} \mathrm{C}$. We placed an $18 \mathrm{~W}$ daylight lamp $8 \mathrm{~cm}$ above the aquarium.

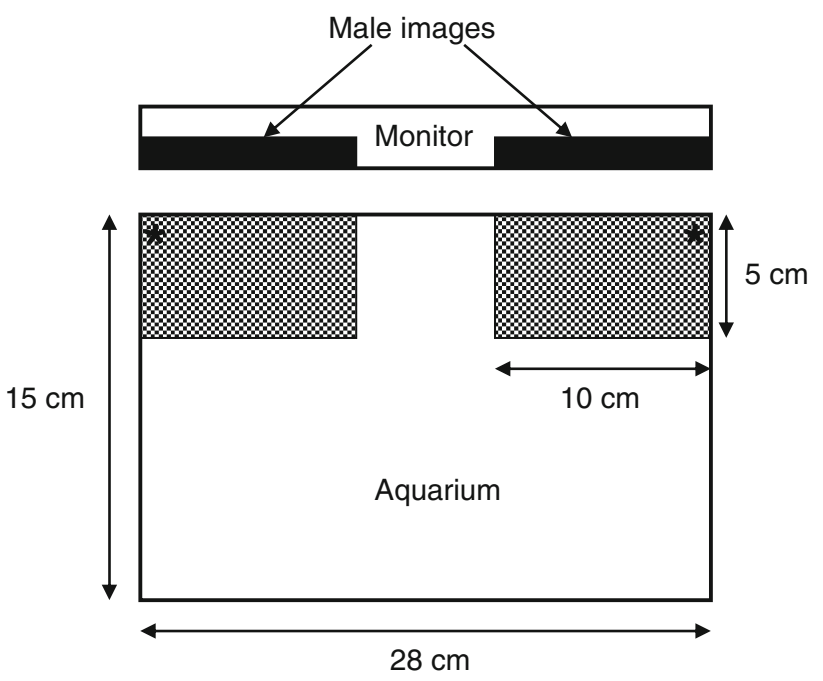

Fig. 1 Experimental apparatus for the female preference test. Shaded areas indicate preference zones. Asterisks at the corners of preference zones represent the positions of stimulus water provided
A bottle $(18 \times 7 \mathrm{~cm})$ that contained water with the olfactory stimulus was connected to a 3-mm-diameter silicone tube. Stimulus water was dropped from the tube to the water surface at the corner of one preference zone in the aquarium (Fig. 1). We placed two bottles, for the right and left preference zones, above the daylight lamp. Water flow was maintained at $8 \mathrm{ml} / \mathrm{min}$ using a clamp. In a preliminary experiment using water stimuli with or without the odor of food, female preference for water with the odor of food could be detected using this apparatus (Wilcoxon signed-ranks test, $T=3, n=10$ females, $P=0.01)$. We covered the experimental apparatus with a dark screen to prevent any external distractions. Observations were carried out through an aperture $(5 \times 12 \mathrm{~cm})$ in the screen.

\section{Experimental procedures}

We introduced a female into the experimental aquarium and provided a 10-min acclimation period. After the acclimation period, stimulus water with male odor was added into the aquarium at the corner of one preference zone, and stimulus water without male odor was added at the corner of the other preference zone. The olfactory and visual stimuli were presented simultaneously to the test female. After the female had passed through both preference zones, we started the observation. We measured the time spent by the female in each preference zone over 15-min observation period.

In experiment 1 , we presented blank aquarium images from both right and left sides of the monitor. In experiment 2 , we presented the bright male images from both right and left sides of the monitor. In experiment 3 , we presented the dull male image at the side with the male odor added, and the bright male image at the side without the male odor added.

After each trial, the experimental aquarium was washed with water to prevent confounding effects of the previous trial. To control side bias, the side with male odor added was randomly assigned for each trial. In addition, each female was used only once, and different females were used in the different experiments. We conducted 24 trials for experiment 1, 27 trials for experiment 2, and 31 trials for experiment 3 , respectively.

Statistical analysis

Since the data did not fulfill assumptions of parametric tests such as the normality and homogeneity of variances, we performed Wilcoxon signed-ranks tests to compare the time spent by females with the stimulus with male odor and that without male odor $(\alpha<0.05)$. In addition, we conducted a generalized linear model to further examine the difference between the time spent by females with the 
stimulus with male odor and that without male odor. In the generalized linear model, the time spent by females with each stimulus was a dependent variable, and the stimuli (with or without male odor) as a factor. We performed the generalized linear model with a multinomial distribution and a logit-link function.

To compare the distribution patterns of female preference for male olfactory stimuli in experiments $1-3$, we standardized female preference for male odor by calculating the relative time spent by the female with olfactory stimulus with male odor as (the time spent by the female in one preference zone with male olfactory cues $\times 100) /$ the time spent by the female in both preference zones $(\%)$. Subsequently, we conducted Kolmogorov-Smirnov twosample tests to analyze the difference in the relative time spent by the females with the male olfactory stimuli in experiments $1-3$ with Bonferroni correction $(\alpha<0.016)$. Statistical analysis was conducted using PASW Statistics 18.0 software (SPSS Inc., USA).

\section{Results}

In experiment 1 without male visual stimuli, females spent a greater time in the preference zone with male odor than in the preference zone without male odor (Wilcoxon signed-ranks test; $T=2, P<0.001$; Fig. 2). When the bright male images were presented to females from both right and left sides of the monitor in experiment 2, females also spent a greater time in the preference zone with male odor than in the preference zone without male odor $(T=22, P<0.001$; Fig. 2$)$. In experiment 3 , there was no significant difference in the time spent by females with the dull male image with male odor and the time spent with the bright male image without male odor $(T=243, P=0.92$; Fig. 2$)$. In the generalized linear model, a significant difference between the time spent by females with the stimulus with male odor and that without male odor was found in both experiments 1 (Wald $\chi_{1}^{2}=29.91, P<0.001$ ) and 2 (Wald $\chi_{1}^{2}=29.80, P<0.001$ ). However, in experiment 3 , the difference between the time spent by females with the stimulus with male odor and that without male odor was not significant (Wald $\chi_{1}^{2}=0.001, P=0.98$ ).

The distribution patterns of the relative time spent by females in the preference zone with male odor did not significantly differ between experiments 1 and 2 (Kolmogorov-Smirnov two-sample test; $P=0.56)$. Over $90 \%$ of females (23/24 and $25 / 27$ in experiments 1 and 2 , respectively) spent more than half of the preference time in the zone with male odor added (Fig. 3). However, the distribution patterns of the relative time spent by females in the preference zone with male odor differed significantly between experiments 1 and $3(P=0.008)$, and between experiments 2 and $3(P=0.012)$. In experiment $3,29.0 \%$ of females (9/31) spent more than $90 \%$ of the preference time with the dull male image with male odor, whereas $22.6 \%$ of females (7/31) spent more than $90 \%$ of the preference time with the bright male image without male odor (Fig. 3).
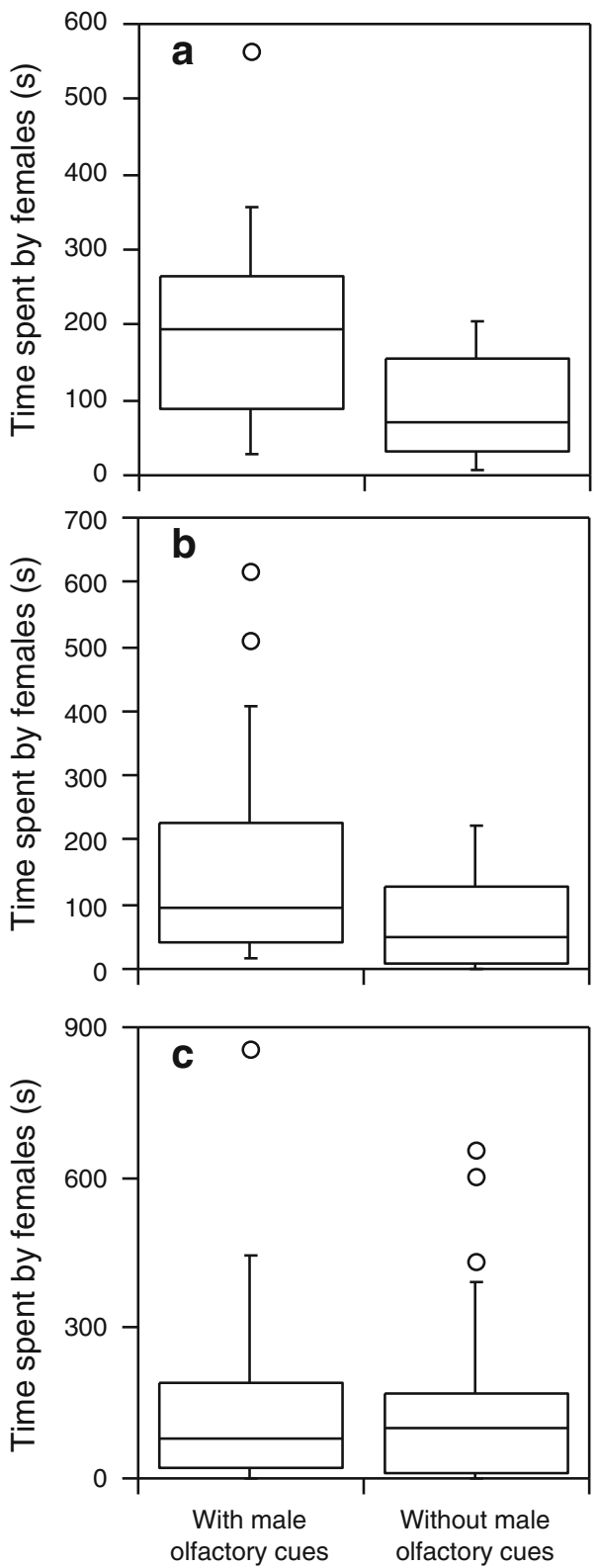

Fig. 2 The time spent by females with each olfactory stimulus in experiment 1 without male visual stimuli (a; $n=24$ females), experiment 2 with identical male visual stimuli (b; $n=27$ females), and experiment 3 with different male visual stimuli $(\mathbf{c} ; n=31$ females). A horizontal line in a box indicates median, the box indicates 75 and 25 percentiles, a bar indicates range, and a circle indicates outlier 

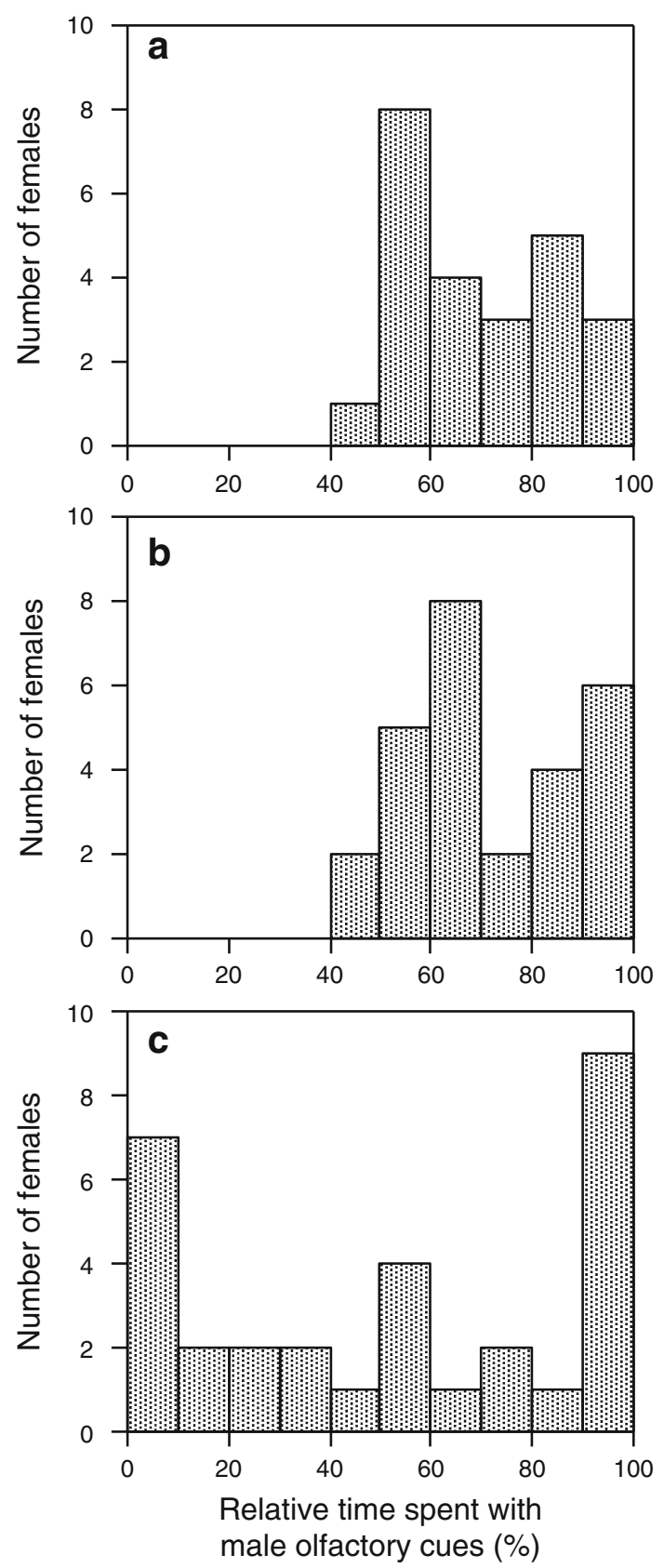

Fig. 3 Distribution patterns of the relative time spent by females with male olfactory stimuli in experiment 1 without male visual stimuli (a), experiment 2 with identical male visual stimuli (b), and experiment 3 with different male visual stimuli (c)

\section{Discussion}

In this study, female guppies preferred water containing male odor to water without male odor, when male visual stimuli were absent. In addition, females also preferred water containing male odor to water without male odor when identical male visual images were present. These results suggest that in the guppy, females may be able to recognize potential mates of conspecifics solely by olfactory cues similar to some other fishes (Kodric-Brown and Strecker 2001; Hankison and Morris 2003). It is also possible that female guppies choose mates using male olfactory cues when males have similar appearances with other males.

However, females in experiment 3 did not show a significant difference in preference between at the dull male image with male odor and the bright male image without male odor. In addition, the distribution patterns of the relative time spent by females with male olfactory cues showed that females in experiments 1 and 2 usually spent more than half of time to the side with male odor. However, in experiment 3 , the distribution pattern of the relative time spent by females with male olfactory cues seems to be bimodal; some females in experiment 3 spent most of the time with the dull male image with male odor, while some other females spent most of the time with the bright male image without male odor. The remaining females showed no clear preference for either of the male stimuli.

The results obtained in experiment 3 may be explained by the individual variation in the relative importance of information gleaned from male olfactory and visual cues. Since the orange spot size of male guppies is a heritable trait (Houde 1992; Brooks and Endler 2001), females that mate with males with large orange spots should produce attractive sons with large orange spots. In addition, the offspring of males with large orange spots are more successful at evading predators than the offspring of males with small orange spots (Evans et al. 2004b). Moreover, color saturation of orange spots is known to reflect algalsearching ability of male guppies (Karino et al. 2007), and algal-searching ability is a heritable trait (Karino et al. 2005). The consumption of algae enhances male orange spot coloration as well as growth in both sexes in guppies (Karino and Haijima 2004). Therefore, by choosing mates using visual cues of male orange spots, females can produce higher quality offspring.

Females of some animals can ascertain the genetic compatibility of potential mates (such as the MHC) using olfactory cues (Egid and Brown 1989; Landry et al. 2001; Aeschlimann et al. 2003; Forsberg et al. 2007). In experiment 3 in this study, if the water with male odor conveyed the olfactory cues of genetically compatible males to females, then the females should have preferred the water with male odor. However, if the water with male odor conveyed the olfactory cues of genetically incompatible males to females, the females should have prioritized male visual cues over male olfactory cues. Female preference for male olfactory cues may have varied between individuals due to possible differences in genetic compatibility between the males and females. The genetic compatibility via male olfactory cues was not investigated in this study; 
therefore, further research is required to test this possibility.

Alternatively, the variation in female preferences for male olfactory and visual cues in experiment 3 may have reflected individual differences in the sensitivity of their sensory systems. Individual differences in olfactory sensitivity within species are known in some animals (Saucier et al. 1991; Kraemer and Apfelbach 2004; HasinBrumshtein et al. 2009). If females possess sensitive olfactory sensory systems, they may prioritize male olfactory cues in mate choice because they can reliably assess the quality of potential mates. However, if females have olfactory sensory systems with low sensitivity, they may use male visual cues as the primary criterion in their mate choice decision.

In conclusion, this study demonstrated that female guppies preferred water with male odor to water with no male odor when male visual stimuli were kept constant. In addition, the relative importance of male olfactory and visual cues varied between females. Future studies should further examine the relative importance of olfactory and visual cues in female guppy mate preference by using more distinctive stimuli than those used in this study, such as olfactory stimuli from healthy males and from parasitized males, or olfactory stimuli from bright males and from dull males. These studies may indicate that particular sensory signals convey which types of information about the males to females.

Acknowledgments We are grateful to anonymous reviewers for their useful comments on earlier version of the manuscript and to N. Hayashi and $\mathrm{H}$. Kudo for their help to this study. This study is supported in part by a Grant-in-Aid for Scientific Research (\#23570020) to KK from the Japan Society for the Promotion of Science.

\section{References}

Aeschlimann PB, Häberli MA, Reusch TB, Boehm T, Milinski M (2003) Female sticklebacks Gasterosteus aculeatus use selfreference to optimize MHC allele number during mate selection. Behav Ecol Sociobiol 54:119-126

Agbali M, Reichard M, Bryjová A, Bryja J, Smith C (2010) Mate choice for nonadditive genetic benefits correlate with MHC dissimilarity in the rose bitterling (Rhodeus ocellatus). Evolution 64:1683-1696

Andersson M (1994) Sexual selection. Princeton University Press, New Jersey

Andersson M, Simmons LW (2006) Sexual selection and mate choice. Trends Ecol Evol 21:296-302

Bahr A, Sommer S, Mattle B, Wilson AB (2012) Mutual mate choice in the potbellied seahorse (Hippocampus abdominalis). Behav Ecol 23:869-878

Brooks R, Endler JA (2001) Direct and indirect sexual selection and quantitative genetics of male traits in guppies (Poecilia reticulata). Evolution 55:1002-1015

Candolin U (2003) The use of multiple cues in mate choice. Biol Rev 78:575-595
Constanzo K, Monteiro A (2007) The use of chemical and visual cues in female choice in the butterfly Bicyclus anynana. Proc R Soc Lond B 274:845-851

Egid K, Brown JL (1989) The major histocompatibility complex and female mating preferences in mice. Anim Behav 38:548-550

Endler JA, Houde AE (1995) Geographic variation in female preferences for male traits in Poecilia reticulata. Evolution 49:456-468

Evans JP, Bisazza A, Pilastro A (2004a) Female mating preferences for colourful males in a population of guppies subject to high predation. J Fish Biol 65:1154-1159

Evans JP, Kelley JL, Bisazza A, Finazzo E, Pilastro A (2004b) Sire attractiveness influences offspring performance in guppies. Proc R Soc Lond B 271:2035-2042

Fisher HS, Rosenthal GG (2006) Female swordtail fish use chemical cues to select well-fed mates. Anim Behav 72:721-725

Forsberg LA, Dannewitz J, Petersson E, Grahn M (2007) Influence of genetic dissimilarity in the reproductive success and mate choice of brown trout-females fishing for optimal MHC dissimilarity. J Evol Biol 20:1859-1869

Grether GF (2000) Carotenoid limitation and mate preference evolution: a test of the indicator hypothesis in guppies (Poecilia reticulata). Evolution 54:1712-1724

Guevara-Fiore P, Skinner A, Watt PJ (2009) Do male guppies distinguish virgin females from recently mated one? Anim Behav 77:425-431

Häberli MA, Aeschlimann PB (2004) Male traits influence odourbased mate choice in the three-spined stickleback. J Fish Biol 64:702-710

Hamilton WD, Zuk M (1982) Heritable true fitness and bright birds: a role for parasites? Science 218:384-387

Hankison SJ, Morris MR (2002) Sexual selection and species recognition in the pygmy swordtail, Xiphophorus pygmaeus: conflicting preferences. Behav Ecol Sociobiol 51:140-145

Hankison SJ, Morris MR (2003) Avoiding a compromise between sexual selection and species recognition: female swordtail fish assess multiple species-specific cues. Behav Ecol 14: 282-287

Hasin-Brumshtein Y, Lancet D, Olender T (2009) Human olfaction: from genomic variation to phenotypic diversity. Trends Genet $25: 178-184$

Heushele J, Manneria M, Gienapp P, Candolin U (2009) Environment-dependent use of mate choice cues in sticklebacks. Behav Ecol 20:1223-1227

Houde AE (1987) Mate choice based upon naturally occurring color pattern variation in a guppy population. Evolution 41:1-10

Houde AE (1992) Sex-linked heritability of a sexually selected character in a natural population of Poecilia reticulata (Pisces: Poeciliidae) (guppies). Heredity 69:229-235

Houde AE (1997) Sex, color, and mate choice in guppies. Princeton University Press, New Jersey

Johansson BG, Jones TM (2007) The role of chemical communication in mate choice. Biol Rev 82:265-289

Karino K, Haijima Y (2004) Algal-diet enhances sexual ornament, growth and reproduction in the guppy. Behaviour 141:585-601

Karino K, Utagawa T, Shinjo S (2005) Heritability of the algalforaging ability: an indirect benefit of female mate preference for males' carotenoid-based coloration in the guppy, Poecilia reticulata. Behav Ecol Sociobiol 59:1-5

Karino K, Shinjo S, Sato A (2007) Algal-searching ability in laboratory experiments reflects orange spot coloration of the male guppy in the wild. Behaviour 144:101-113

Karino K, Shimada Y, Kudo H, Sato A (2010) Relative importance of the area and intensity of the orange spots of male guppies Poecilia reticulata as mating traits preferred by females. J Fish Biol 77:299-307 
Kodric-Brown A (1989) Dietary carotenoids and male mating success in the guppy: an environmental component to female choice. Behav Ecol Sociobiol 25:393-401

Kodric-Brown A, Strecker U (2001) Responses of Cyprinodon maya and $C$. labiosus females to visual and olfactory cues of conspecific and heterospecific males. Biol J Linn Soc 74:541-548

Kraemer S, Apfelbach R (2004) Olfactory sensitivity, learning and cognition in young adult and aged male Wistar rats. Physiol Behav 81:435-442

Landry C, Garant D, Duchesne P, Bernatchez L (2001) 'Good genes as heterozygosity': the major histocompatibility complex and mate choice in Atlantic salmon (Salmo salar). Proc R Soc Lond B 268:1279-1285

McLennan DA (2003) The importance of olfactory signals in the gasterosteid mating system: sticklebacks go multimodal. Biol J Linn Soc 80:555-572

McLennan DA, Ryan MJ (2008) Female swordtails, Xiphophorus continens, prefer the scent of heterospecific males. Anim Behav 75:1731-1737

Nicoletto PF, Kodric-Brown A (1999) The use of digitally-modified videos to study the function of ornamentation and courtship in the guppy, Poecilia reticulata. Environ Biol Fish 56:333-341

Plenderleith M, van Oosterhout C, Robinson RL, Turner GF (2005) Female preference for conspecific males based on olfactory cues in a Lake Malawi cichlid fish. Biol Lett 1:411-414

Pryke SR, Andersson S, Lawes MJ (2001) Sexual selection of multiple handicaps in the red-collared widowbird: female choice of tail length but not carotenoid display. Evolution 55:1452-1463

Saucier D, Astic L, Rioux P (1991) The effects of early chronic exposure to sublethal copper on the olfactory discrimination of rainbow trout, Oncorhynchus mykiss. Environ Biol Fish 30:345-351

Shohet AJ, Watt PJ (2004) Female association preferences based on olfactory cues in the guppy, Poecilia reticulata. Behav Ecol Sociobiol 55:363-369

Simmons LW, Thomas ML, Simmons FW, Zuk M (2013) Female preferences for acoustic and olfactory signals during courtship: male crickets send multiple messages. Behav Ecol 24:1099-1107

Strandh M, Westerdahl H, Pontarp M, Canbäck B, Dubois MP, Miquel C, Taberlet P, Bonadonna F (2012) Major histocompatibility complex class II compatibility, but not class I, predicts mate choice in a bird with highly developed olfaction. Proc R Soc Lond B 279:4457-4463

Wagner WE, Basolo AL (2007) The relative importance of different direct benefits in the mate choices of a field cricket. Evolution 61:617-622

Wong BBM, Fisher HS, Rosenthal GG (2005) Species recognition by male swordtails via chemical cues. Behav Ecol 16:818-822

Zahavi A (1975) Mate selection-a selection for a handicap. J Theor Biol 53:205-214 